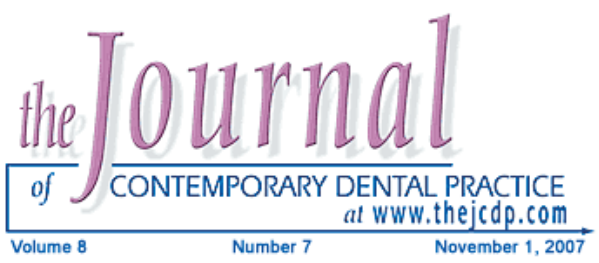

\title{
Positioning Magnets on a Multiple/Sectional Maxillofacial Prosthesis
}

\author{
Marcelo Coelho Goiato, DDS, MS, PhD; \\ Aline Úrsula Rocha Fernandes, DDS, MS; \\ Daniela Micheline dos Santos, DDS; \\ Valentim Adelino Ricardo Barăo, DDS
}

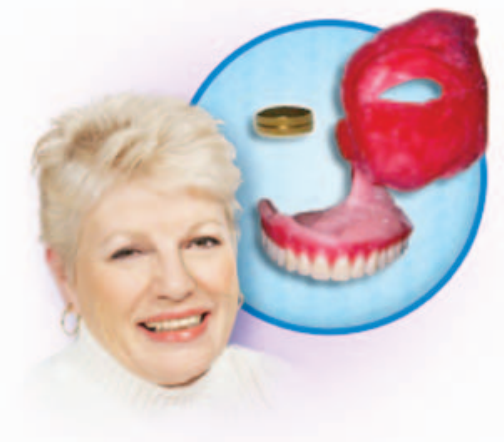

Abstract

Aim: The aim of this report is to describe a quick and simple method of positioning retention magnets when deformed patients are rehabilitated with an oculopalpebral prostheses attached to a maxillary denture/obturator.

Background: In patients with deformities requiring complex rehabilitations, the use of magnets is the most efficient means of providing combined prostheses with retention quality and stability. Usually prostheses with magnets are in sections and have a magnet in each section. When the sections are put together properly, the magnets are attracted to each other and retain the sections.

Report: An edentulous patient presented for a post-surgical evaluation of a maxillofacial prosthesis used to repair a partial maxillectomy and left orbital exoneration which removed all adjacent tissues leaving an open communication between the oral, nasal, and orbital cavities. The proposed treatment plan included construction of a maxillary complete denture with a palatal obturator and a mandibular complete denture. Magnets were used to attach the oculopalpebral prosthesis to the maxillary denture/obturator.

Summary: Use of retention magnets simplify the clinical and laboratorial phase, retains the denture, and makes it stable and comfortable for the patient. This treatment is one successful approach to the restoration of oral function and increases the patient's quality of life.

Keywords: Prosthesis maxillofacial, magnets, silicone

Citation: Goiato MC, Fernandes AÚR, dos Santos DM, Barão VAR. Positioning Magnets on a Multiple/ Sectional Maxillofacial Prosthesis. J Contemp Dent Pract 2007 November; (8)7:101-107.

(c) Seer Publishing 


\section{Introduction}

Head and neck cancer treatment frequently leaves the patient with some facial deformity due to extensive muscle and bone loss which, in turn, can cause the patient to become depressed and isolated. ${ }^{1}$ As plastic surgery is not advisable, prosthetic reconstruction is the only possible solution. Maxillofacial prostheses have the advantage of not only improving the patient's appearance but also enabling early rehabilitation. These prostheses make it possible to inspect the affected area, shorten surgery and hospitalization time, lower treatment cost, and allow the patient to be psychosocially re-integrated more quickly. ${ }^{2}$

Radical maxillectomies often leave extensive defects involving hard and soft tissues resulting in communication between the oral and nasal cavities. ${ }^{3}$ Patients with this type of defect generally have difficulty speaking, breathing, and deglutition. In addition, they show less sensitivity in the area operated on, poor lip competence, trismus, and xerostomia. ${ }^{4}$ The lack of support, retention, and stability of prostheses often found in mutilated patients presents a clinical challenge.

The use of magnets is the most efficient means of providing combined prostheses with retention and stability in patients with deformities requiring complex rehabilitations. ${ }^{5,6}$ The majority of prostheses with magnets are sectioned and have a magnet in each section. When the sections are assemble properly, the magnets are attracted to each other and retain the sections. ${ }^{6}$

The aim of this work is to describe a quick and simple method of magnet positioning in cases where deformed patients are rehabilitated with an oculopalpebral prostheses attached to a maxillary denture/obturator and to demonstrate the contribution of prosthetic rehabilitation has on improving a patient's quality of life.

\section{Case Report}

A 78-year-old edentulous woman patient came for a post surgery prosthetic evaluation. Her medical history showed a partial maxillectomy and left orbital exoneration which removed all adjacent tissues (Figure 1). Therefore, there was open communication between the oral, nasal, and orbital cavities (Figure 2). The mutilation left the patient with esthetical and functional

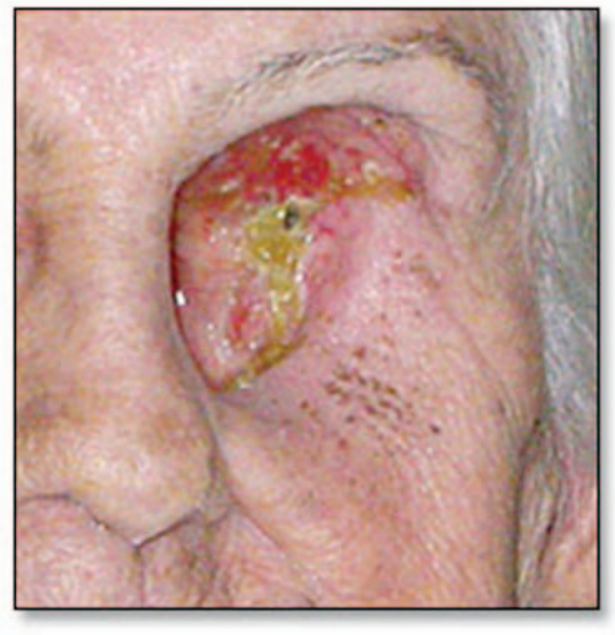

Figure 1. Anterior view of the anatomical defect following the maxillectomy.

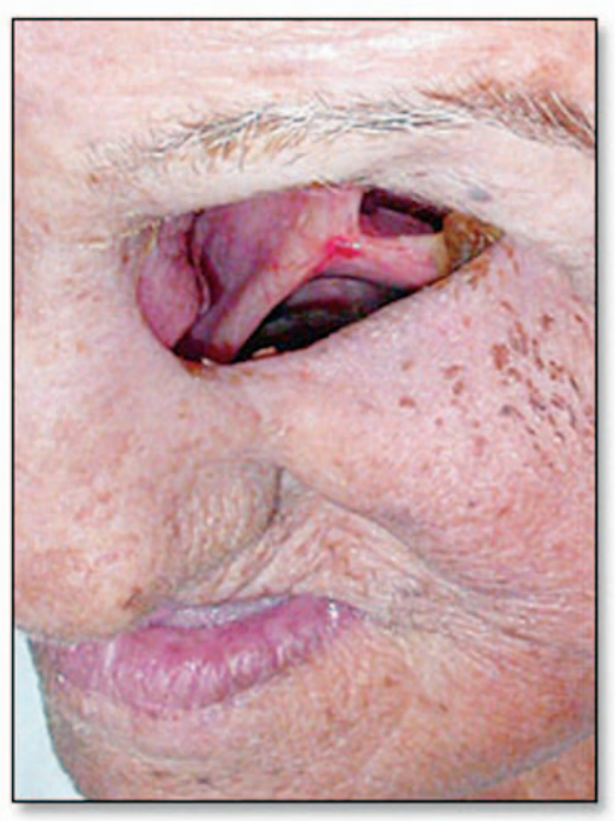

Figure 2. Oblique view of the anatomical defect showing the communication with the nasal cavity.

problems, such as difficulty with breathing, chewing, deglutition, speech as well as serious psychosocial problems.

After considering the case, the proposed treatment plan was to construct a maxillary complete denture with a palatal obturator and mandibular complete denture, as well as an oculopalpebral prosthesis, which would be 
attached to the palatal obturator with cobalt samarium magnets (Magnetos Gerais; Magnetos Ferais Ind. Com. Ltd, São Paulo, SP, Brazil).

Treatment was started by making an impression of the patient's face using irreversible hydrocolloid (Jeltrate Plus; Dentsply Ind. Com. Ltd, Petrópolis, RJ, Brazil). An individual mold of Type III stone plaster (Gesso-Rio; Orlando Antonio Bussioli-ME, Rio Claro, SP, Brazil) was then fabricated from the impression. This plaster facial mask was used for sculpturing the prosthetic elements. These anatomical shapes were created in pink wax using a No. 7 wax spatula (Wilson Polidental Ind. Com. Ltd, Cotia, SP, Brazil). Care was taken to retain the same characteristics of the contralateral side of the face. An extension was made on the internal area of the wax model to bring it closer to the superior portion of the palatal obturator denture.

The buccal prostheses were made simultaneously with the facial prosthesis. Next, the anatomical models were created then a functional mixed impression was done. For the fiber mucosa impression, a zinc oxide Eugenol impression paste (Lysanda Produtos Odontológicos Ltd, São Paulo-SP, Brazil) was used along with low viscosity condensation silicone of (Oranwash $L$, Zhermack S.p.A, Badia Polesine, Italy) for the communication area. Using the resultant models, the complete prosthesis was made in accordance with the procedure recommended by Zarb et al. ${ }^{8}$

Before testing the prostheses functionally and esthetically, magnets were fixed with wax to the inferior part of the facial prosthesis extension and to the most superior part of the palatal obturator denture (Figure 3).

A trial fit was then performed to assess all the functional and esthetical requirements and to determine if the obturator portion of the maxillary denture sealed the anatomical imperfections perfectly. In addition, the wax model sculpture of the facial prosthesis was accessed to determine if it retained the same characteristics of the

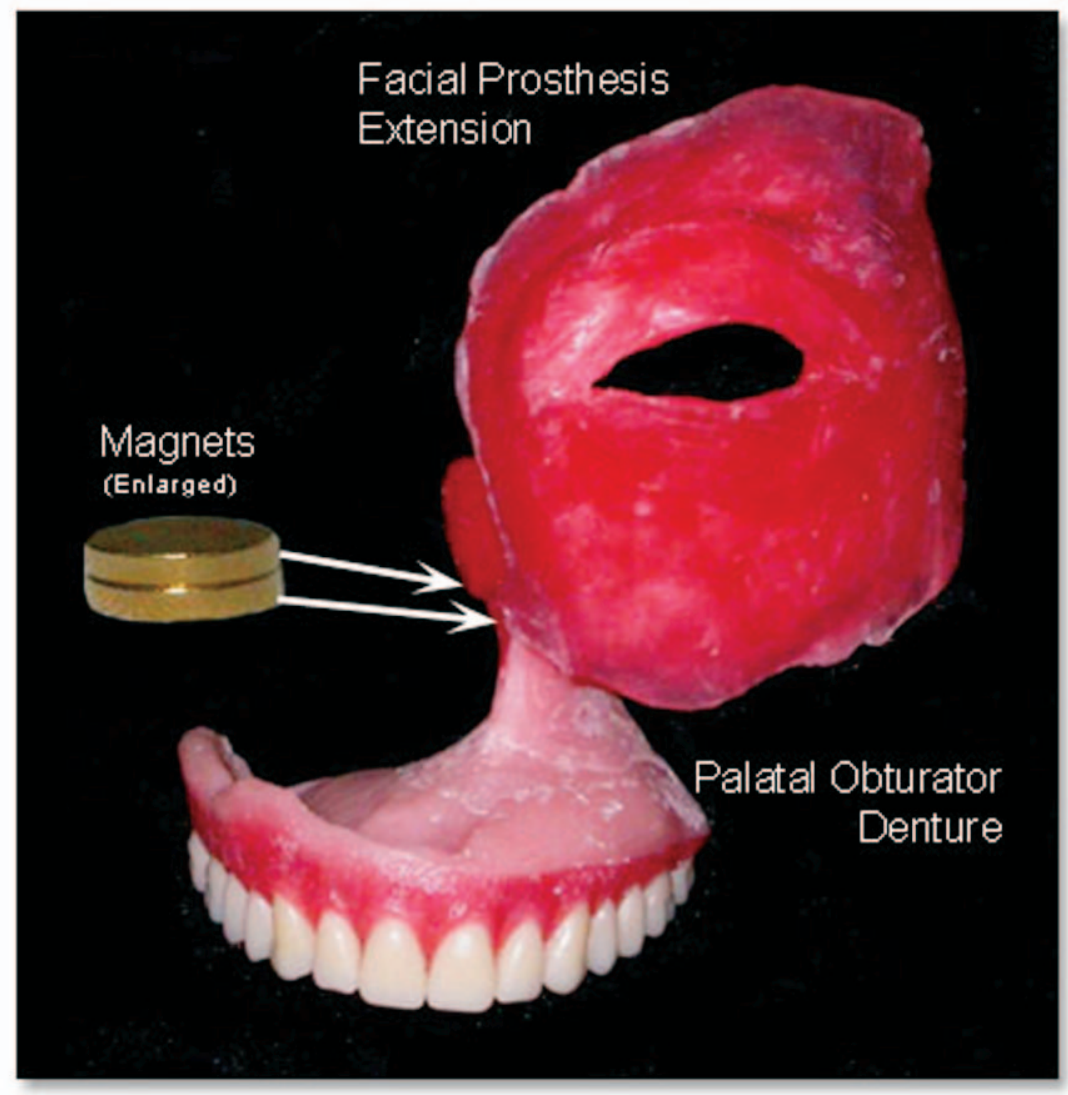

Figure 3. Location of magnet placement between the facial prosthesis extension and the palatal obturator denture. 
contralateral side. It was noted prostheses retention was better due to the magnets.

After functional and esthetical testing, the magnets were removed and the dentures were processed and finished. An ocular prosthesis was also created for the facial prosthesis. The wax oculopalpebral prosthesis was placed in a flask, and its mold was filled with silicon (Silastic MDX 4-4210, Dow Coming Corporation, Midland, MI, USA) pigmented with ceramic powder.

When the intra-oral and facial prostheses had been completed, they were disinfected with gluconic of chlorhexidine gluconate (2\%) for a period of ten minutes and then washed in water. The intra-oral prosthesis was inserted, and compression areas of the resin base were relieved for patient comfort and occlusal adjustments made to improve efficiency and during mastication and provide better stability of the prosthesis. ${ }^{8,9}$

At the time of insertion, the facial prosthesis and the magnets were positioned again. Self-curing acrylic resin (Jet Clássico, Artigos Odontológicos Clássico Ltd, São Paulo-SP, Brazil) was initially used to attach a magnet on the superior part of the palatal obturator prosthesis. Highlighter paste (Mizzy Inc., Cherry Hill , NJ, USA) was brushed onto its surface, and the facial prosthesis was positioned on the patient's face to demarcate the area of most contact. On the demarcated area of the facial prosthesis extension, the second magnet was positioned with silicon (Figure 4).

After the prostheses were installed, functional tests were done; it was observed there was good retention and stability as well as adequate adjustment of the facial prosthesis edges to the patient's face. Figure 5 shows the prosthesis after one year of use.

\section{Discussion}

The problems created by maxillectomy defect are chewing, speech, and swallowing. ${ }^{10}$ Moreover, the patient usually develops esthetic and psychological problems. ${ }^{11}$ Kornblith et al. ${ }^{12}$ reported satisfactory functioning of an obturator prosthesis significantly contributes to improved psychological well-being and a quality of life for maxillectomy patients. The use of a maxillofacial prosthesis can offer good cosmetic and functional

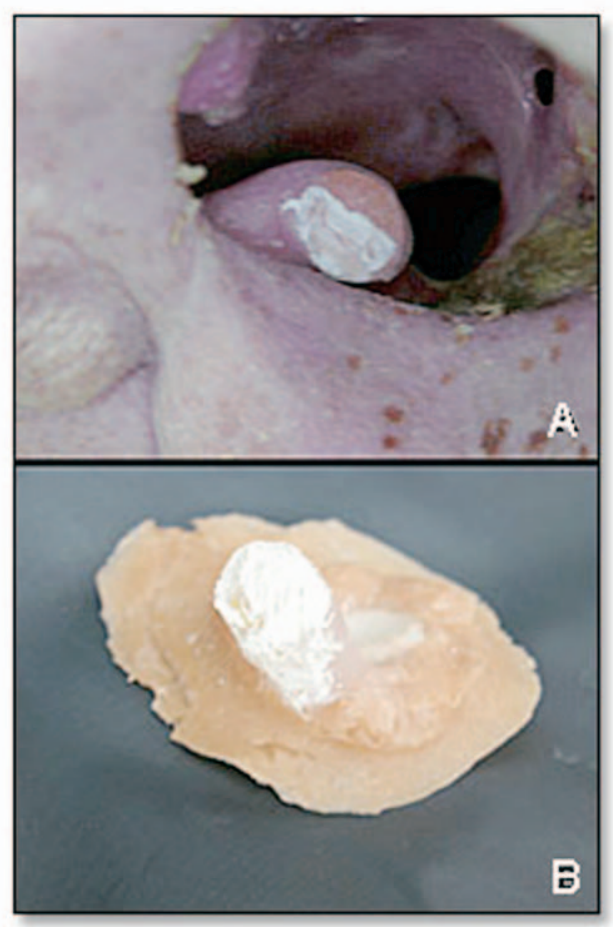

Figure 4. Positioning of the retention magnets. A. Highligher paste on the superior aspect of the palatal obturator prosthesis. B. Transfer of the paste to the facial prosthesis extension to demarcate the location for the second magnet.

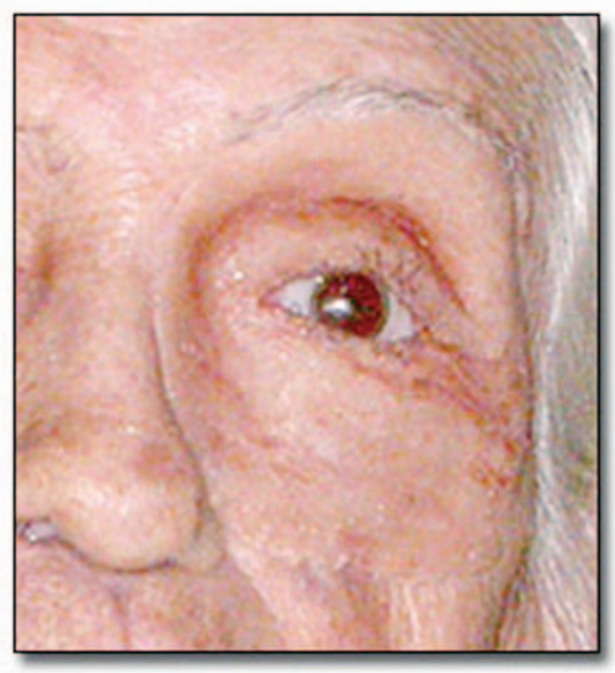

Figure 5. Facial prosthesis in place after one year of use.

results, although this surgery can be a challenge to the professional.

The dentist's psychological attitude towards a mutilated patient is of great importance with regard to gaining his/her confidence. In 
prosthetic treatment significant understanding and cooperation on the patient's part are needed. These patients are resentful about the lesion and its impact on them and generally have associated psychological problems. The maxillofacial prosthodontist must not show feelings of surprise or repulsion, especially in the face of oncosurgical lesions. They must show optimism with regard to the treatment plan and the prognosis. This positive attitude helps to boost the mutilated patient's morale and improve the opportunity for patient cooperation.

The success of rehabilitative treatment in a patient with extensive resections involving the hard palate, soft palate, and orbital exenteration is directly related to the quality of the prosthesis. ${ }^{10}$ One of the significant problems professionals encounter when fabricating these prostheses is the lack of retention. ${ }^{3}$ In addition, the edges of the facial prosthesis do not always adapt perfectly to the patient's face because of the movement of bordering tissues. Retentive elements, apart from conventional adhesives, are normally required. The use of magnets in multiple/sectional maxillofacial prostheses is an excellent means to bond them together. However, to assure proper retention and effective stability of the prosthesis each section should be sufficiently extended and the magnets positioned properly. ${ }^{13} \mathrm{~A}$ quick and simple method for positioning the magnets, with the use of a highlighting paste to fix them properly, was presented here.

\section{Conclusion}

After the prosthesis was inserted, a meaningful improvement in esthetics and function as well as psychological improvement occurred which facilitated the patient's re-integration into society. The patient reported improvement in prosthesis retention and stability along with improvement in masticatory and speech functions.

\section{References}

1. Weischer T, Nohr CA. A new application for craniofacial implants: wigs. Int J Prosthodont 2000; 13:108-11.

2. Brenner P, Berger A. Epitheses of the face. Handchir Nikrochir Plast Chir 1992; 24:88-92.

3. Wieselmann-Penkner K, Arnetzl G, Mayer W, Bratschko R. Minimizing movement of an orbital prosthesis retained by an obturator prosthesis. J Prosthet Dent 2004; 91:188-90.

4. Cheng AC, Somerville DA, Wee AG. Altered prosthodontic treatment approach for bilateral complete maxillectomy: a clinical report. J Prosthet Dent 2004; 92:120-24.

5. Parel SM, Branemark PI, Ohrnell LO, Svensson B. Remote implant anchorage for the rehabilitation of maxillary defects. J Prosthet Dent 2004; 86:377-81.

6. Barron JB, Rubenstein JE, Archibald D, Manor RE. Two-piece orbital prosthesis. J Prosthet Dent 1983; 49:396-88.

7. Sasaki H, Kinouchi $Y$, Tsutsui H, Karv M, Usshita T. Sectional prostheses connected by samariumcobalt magnets. J Prosthet Dent 1984; 52:556-8.

8. Zarb G, Bolender C, Eckert S, Jacob R, Fenton A, Mericske-Stern R. Prosthodontic treatment for edentulous patients. 12th ed. St. Louis: CV Mosby; 2004. 576p.

9. Dubojska AM, White GE, Pasiek S. The importance of occlusal balance in the control of complete dentures. Quintessence Int 1998; 29:389-94.

10. Rogers SN, Lowe D, McNally D, Brow JS, Vaugban ED. Health-related quality of life after maxillectomy: a comparison between prosthetic obturation and free flap. J Oral Maxillofac Surg 2003; 61: 174-81.

11. Brignoni R, Dominici JT. Na intraoral-extraoral combination prosthesis using na intermediate framework and magnets: A clinical report. J Prosthet Dent 2001; 85:7-11.

12. Konblith AB, Zlotolow IM, Goosen J, Horyn JM, Lerner T, Strong EW, Sahah JP, Spiro RH, Holland JC. Quality of life of maxillectomy patients using an obturator prosthesis. Head Neck 1996; 18:323-34.

13. Öwall B, Käyser AF, Carlsson GE. Prosthodontics. Principles and management strategies. London: Mosby-Wolfe; 1996. p.201-21. 


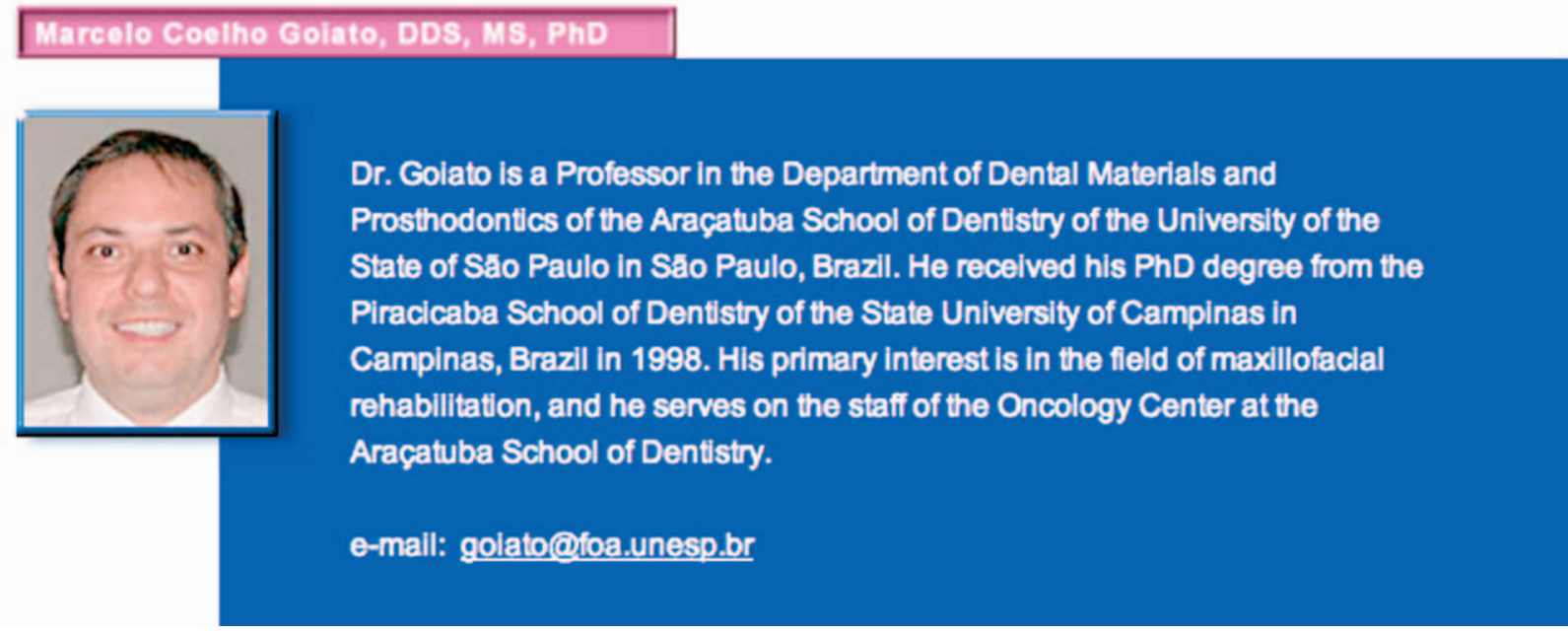

\section{Allno Ursula Rocha Fornandes, DDS, MS}

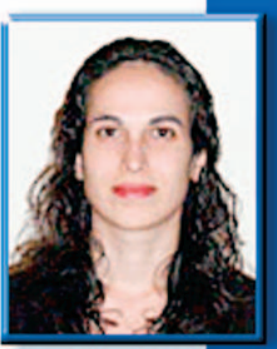

Dr. Fernandes recelved her Masters degree from Araçatuba School of Dentistry of the University of the State of Saio Paulo in Săo Paulo, Brazll in 2004. She is currently a postgraduate student in the Araçatuba School of Dentistry, an Assistant Professor at the University National of the Brasilia, and she serves in the Maxillofacial Rehabilitation Center at the University Hospital of Brasilia, Brazll.

e-mail: allineursula@bol.com.br

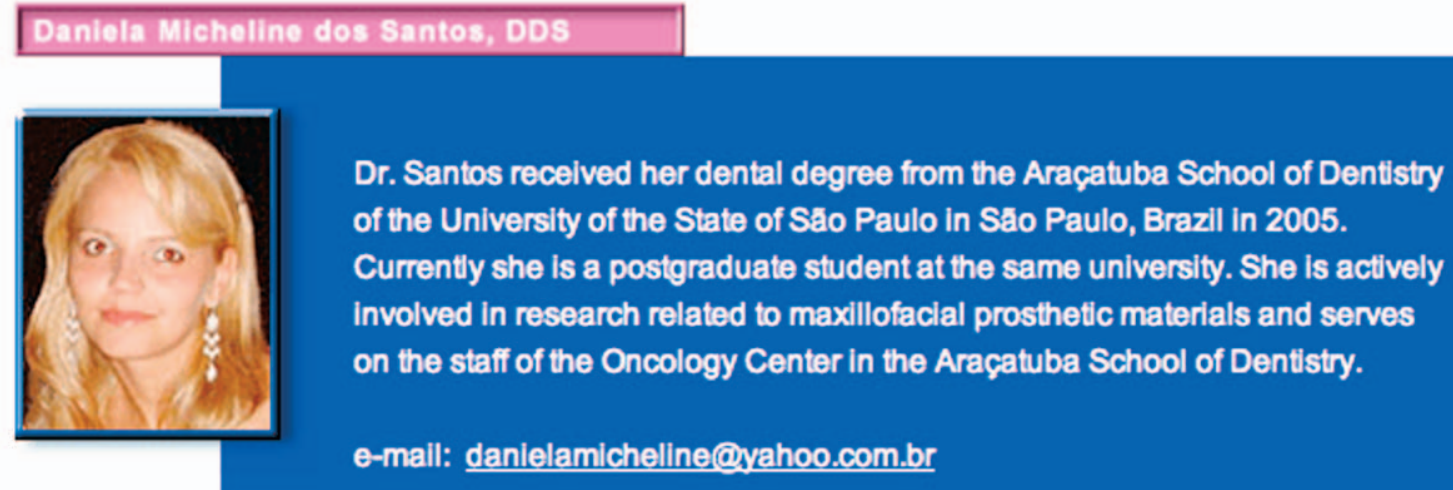




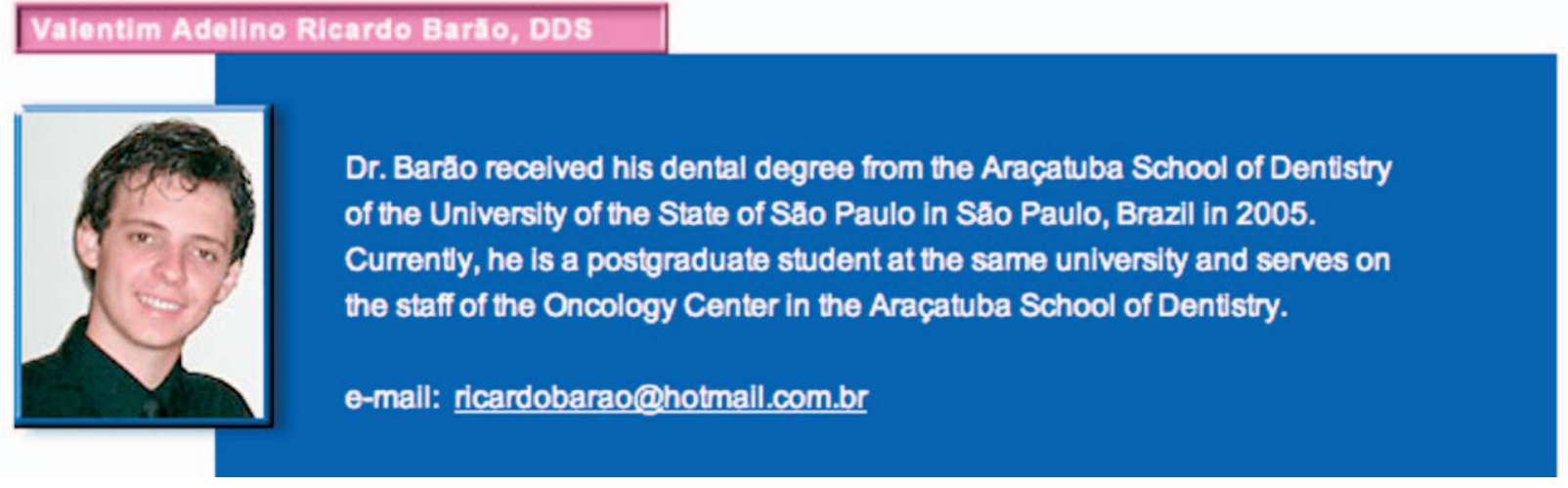

